\title{
Influence of Coolant Pressure Size on Surface Roughness when Stainless Steel Machining
}

\author{
Robert Cep ${ }^{1, *}$, Lenka Cepova ${ }^{1}$, Cristina Stefana Borzan $^{2}$, Jiri Kasal ${ }^{1}$, Marek Sadilek ${ }^{1}$, \\ Dagmar Sokova ${ }^{1}$, Michal Hatala ${ }^{3}$, Jana Petru ${ }^{1}$, Dana Stancekova ${ }^{4}$, Marek Pagac ${ }^{1}$, Jiri \\ Hajnys $^{1}$ and Ondrej Mizera ${ }^{1}$ \\ ${ }^{1}$ VSB-TU Ostrava, 17. listopadu 2172/15, 70800 Ostrava, Czech Republic \\ ${ }^{2}$ Technical University of Cluj Napoca, Boulevard Muncii 103-105, 4000461 Cluj-Napoca, Romania \\ ${ }^{3}$ Technical University in Kosice, Presov, Bayerova 1, 080 01, Slovakia \\ ${ }^{4}$ Zilina University in Zilina, Univerzitná 8215/1, 01026 Zilina, Slovakia
}

\begin{abstract}
The paper is focused on the influence of the coolant pressure on the surface roughness of the workpiece when machining stainless steels. The components were machined on a STAR SR-32J dual spindle machining center and an external cooling unit HYTEK CHAV 160/150AF-F-OL was used for cooling. Two stainless steel components were investigated, namely the gas control valve rod and the high-pressure control valve housing, which require low roughness Ra after machining (less than 0.375 and 0.25 micrometers respectively). The first component was tested at 8 different pressures in the range of $150 \mathrm{bar}-10 \mathrm{bar}$ and the second component at 4 different pressures in the range of 120 bar - 10 bar. The roughness parameters were measured by the contact method using the MITUTOYO Surftest SJ-410 Roughness Tester and the Alicona InfiniteFocus optical microscope. Based on these sample input parameters, it was evaluated how much the pressure affects the surface quality or suggested its reduction due to the high cost of operation of the external high-pressure equipment.
\end{abstract}

\section{Introduction}

In today's modern trends in machining methods, it is necessary to keep up with competitors. There is a range of materials in this area that are difficult to machine. When machining them, special equipment is required for both machining and cooling, which is an integral part of the stainless steel machining process. In the case of stainless steel machining, highpressure cooling is required to achieve the required surface quality under ideal cutting conditions. From a time perspective, high-pressure cooling helps us to speed up the machining process while maintaining the required surface quality $[6,7]$.

The aim was to investigate the effect of high-pressure cooling on the surface roughness of the workpiece when machining stainless steels and to achieve the desired surface roughness, using adequate coolant pressure and streamlining production processes and associated manufacturing costs [8].

* Corresponding author: robert.cep@,vsb.cz 


\section{Used machines and equipment}

\subsection{Machinetool STAR SR-32J}

The STAR SR - 32J CNC machining center from STAR MICRONICS (figure 1) is designed for machining smaller diameter parts and is used, for example, in the aerospace or automotive industries [1]. It has two spindles with a maximum speed of $7000 \mathrm{rpm}$, allowing multiple operations at once. After completing the operations performed on the main spindle, the workpiece subsequently receives the secondary spindle, which performs additional operations independently of the main spindle [1].

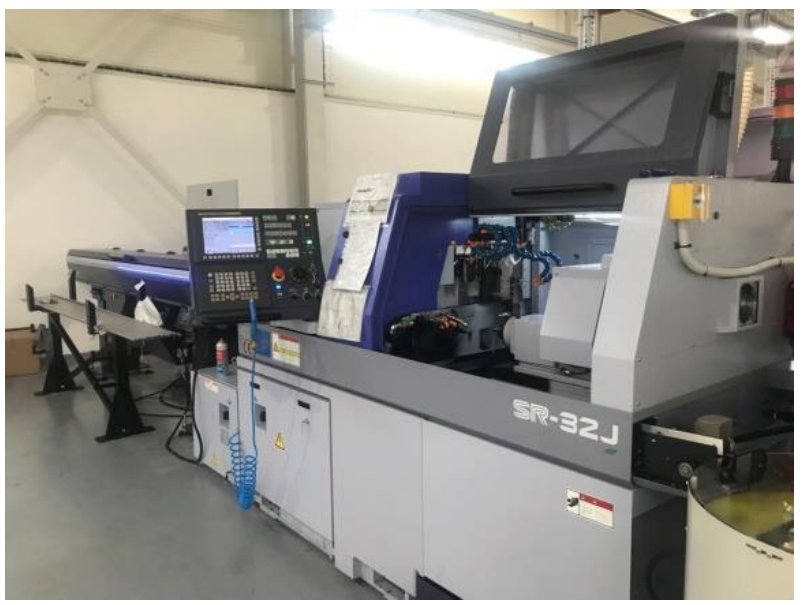

Fig. 1. Machinetool STAR SR-32J

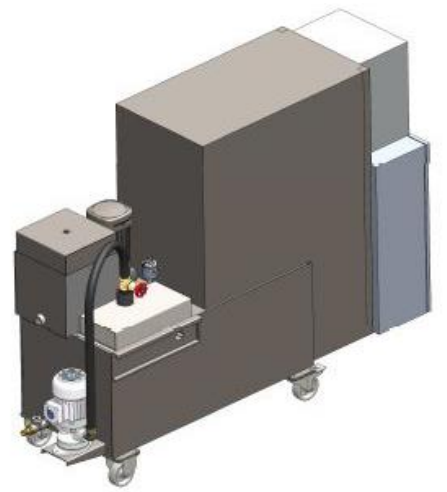

Fig. 2. External cooling unit CHAV 160/150

\subsection{External Cooling Unit CHAV 160/150}

This unit (figure 2) is used for filtration and transport of cutting oil for high-pressure cooling used in machining, especially in multi-spindle automatic machines. The oil is sucked in with a centrifugal pump from the machine tank and delivered through a filter screen to the outlet where a relief valve is located to control the maximum output pressure 
(up to 160 bar). According to the variant, the unit includes a block with oil supply valves up to four tools [2].

\subsection{Surface Roughness equipment MITUTOYO SURFTEST SJ-410}

It is a static roughness meter (figure 3) with a measuring base stand, digital display and printer for almost instantaneous to be modify as printing of measured parameters [3].

\subsection{Non-contact microscope Alicona InfiniteFocus}

The measurement principle of the Alicona InfiniteFocus, see figure 4, consists of optical two-dimensional and three-dimensional scanning of the workpiece surface. As a result, the measurement does not only measure profile roughness, but also provides a comprehensive measurement of roughness. The principle of microscope operation is based on focusing, which vertically scans the surface of the measured component and subsequently evaluates the measured values. The illuminating rings are used for better illumination, resulting in high accuracy $[4,5]$.

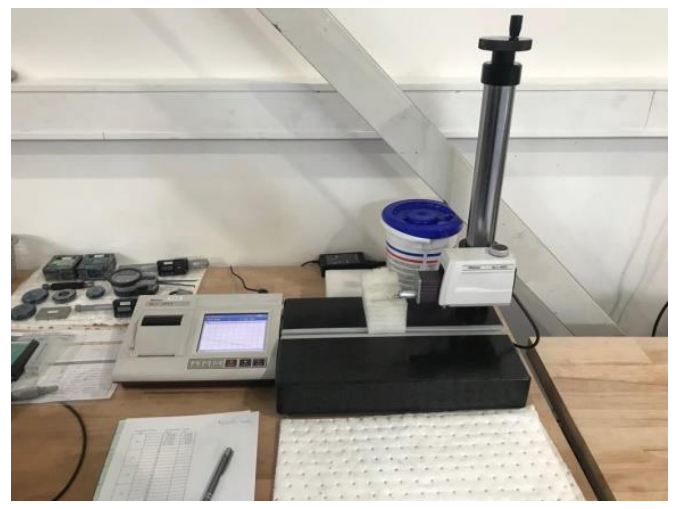

Fig. 3. Mitutoyo SJ-410

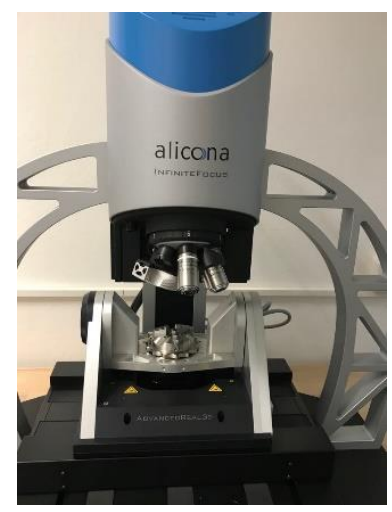

Fig. 4. Alicona InfiniteFocus

\section{Measured workpieces}

\subsection{Component No. 1 - Gas Control Valve Part}

It is part of a gas control valve that operates in a highly aggressive corrosive environment. This experiment deals with the surface quality of the longest diameter component for which the required surface roughness quality is required due to high pressure cooling. The part model can be seen in figure 5 .

\subsection{Component No. 2 - High Pressure Control Valve Housing}

It is a high pressure control valve housing that operates in a very strong corrosive environment. As with the previous section, the experiment deals with the surface roughness quality of the longest diameter component for which the highest quality surface quality is required. The part model can be seen in the following figure 6 . 


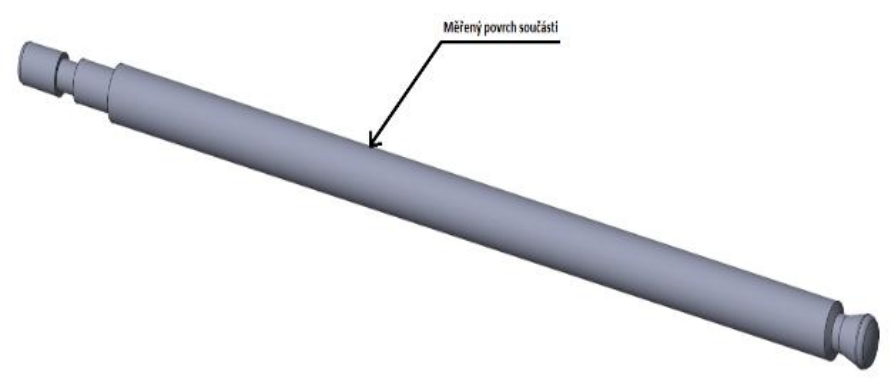

Fig. 5. Component No. 1 - Gas Control Valve Part

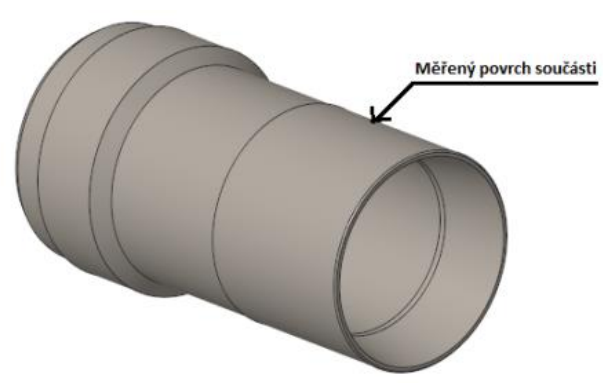

Fig. 6. Component No. 2 - High Pressure Control Valve Housing

\section{Experimental part}

\subsection{Measurement of Part \# 1 by Mitutoyo SJ-410}

For this experiment, samples were produced at eight different pressures. All samples were then measured with a roughness gauge, which was used from the highest working pressure, which is also applied in production, to $150 \mathrm{bar}$, to the lowest possible working pressure (10 bar) of high-pressure equipment CHAV 150/160. The given surface roughness limit of the tested functional area is $\mathrm{Ra}=0.375 \mu \mathrm{m}$.

Table 1. Measured Results on Roughness Tester MITUTOYO for Part 1

\begin{tabular}{|c|c|c|}
\hline $\begin{array}{c}\text { Pressure } \\
(\mathbf{b a r})\end{array}$ & $\begin{array}{c}\text { Surface Roughness } \\
\mathbf{R a}(\boldsymbol{\mu \mathbf { m }})\end{array}$ & $\begin{array}{c}\text { Selective Standard } \\
\text { Deviation }(\boldsymbol{\mu \mathbf { m }})\end{array}$ \\
\hline 150 & 0,189 & $\pm 0,0709$ \\
\hline 130 & 0,167 & $\pm 0,0306$ \\
\hline 110 & 0,157 & $\pm 0,0454$ \\
\hline 90 & 0,148 & $\pm 0,0304$ \\
\hline 70 & 0,129 & $\pm 0,0189$ \\
\hline 50 & 0,133 & $\pm 0,0199$ \\
\hline 30 & 0,146 & $\pm 0,0303$ \\
\hline 10 & 0,130 & $\pm 0,0095$ \\
\hline
\end{tabular}


Example of standard deviation calculation

Selection average:

$$
\bar{x}=\frac{\sum_{i=1}^{n} d_{i}}{n}=\frac{0,945}{5}=0,189 \mu \mathrm{m}
$$

Deviation $\Delta x$ :

$$
\Delta x_{i}=x_{i}-\bar{x}=0,167-0,189=-0,022 \mu m
$$

Quadratic deviation $\Delta x_{i}^{2}$ :

$$
\Delta x_{i}^{2}=\left(x_{i}-\bar{x}\right)^{2}=(-0,022-0)^{2}=0,000484 \mu m
$$

Selection Standard Deviation:

$$
s\left(x_{i}\right)=\sqrt{\frac{\sum_{i=1}^{n}\left(x_{i}-\bar{x}\right)^{2}}{n-1}}=\sqrt{\frac{0,020102}{5-1}}=0,0709 \mu \mathrm{m}
$$

The original assumption was that even when the working pressure was reduced from 150 bar to about half $(70$ bar $)$, the surface roughness values measured would fall below the limit of the required surface roughness Ra $0.375 \mu \mathrm{m}$. However, this did not happen even when the pressure was reduced to a minimum of 10 bar for which an average surface roughness value of $\mathrm{Ra} 0.13 \mu \mathrm{m}$ was measured. For all eight pressures examined, the roughness value $\mathrm{Ra}$ falls only below the $\mathrm{Ra}$ limit of $0.2 \mu \mathrm{m}$ at a pressure of 150 bar and 130 bar, which is still far from the limit of the roughness required. Further, the roughness deviation calculations for each surface under investigation at a given working pressure were performed. Despite the gradual reduction of the working pressure, the required surface roughness was maintained for all measured samples. The part no. 1 has a diameter of $2 \mathrm{~mm}$, ie the chip removal is minimal in this case. Thus, the cooling pressure did not affect both the surface roughness and the desired chemical and physical properties of the material. In the case of component 1 , it is thus contemplated to reduce the pressure of the coolant and the associated costs of operating the high pressure device.

\subsection{Measurement of Part \# 2 by Mitutoyo SJ-410}

In part 2, samples were produced at only 4 different pressures. All samples were subsequently measured sequentially from the highest working pressure of 120 bar for this component to the minimum possible working pressure developed by the CHAV 150/160 refrigerant, which was 10 bar. Measurements were made only at 4 different pressures due to the economically higher cost of manufacturing part \# 2. The given surface roughness limit of the tested functional area is $\mathrm{Ra}=0.25 \mu \mathrm{m}$.

Table 2. Measured Results on Roughness Tester MITUTYOYO for Part 2

\begin{tabular}{|c|c|c|}
\hline $\begin{array}{c}\text { Pressure } \\
(\mathbf{b a r})\end{array}$ & $\begin{array}{c}\text { Surface Roughness } \\
\mathbf{R a}(\boldsymbol{\mu \mathbf { m }})\end{array}$ & $\begin{array}{c}\text { Selective Standard } \\
\text { Deviation }(\boldsymbol{\mu m})\end{array}$ \\
\hline 120 & 0,174 & $\pm 0,0212$ \\
\hline 80 & 0,205 & $\pm 0,0078$ \\
\hline 30 & 0,284 & $\pm 0,0212$ \\
\hline 10 & 0,311 & $\pm 0,0757$ \\
\hline
\end{tabular}


Example of standard deviation calculation

Selection average

$$
\bar{x}=\frac{\sum_{i=1}^{n} d_{i}}{n}=\frac{0,348}{2}=0,174 \mu \mathrm{m}
$$

Deviation $\Delta \mathrm{xi}$

$$
\Delta x_{i}=x_{i}-\bar{x}=0,159-0,174=-0,015 \mu m
$$

Quadratic deviation $\Delta x_{i}^{2}$

$$
\Delta x_{i}^{2}=\left(x_{i}-\bar{x}\right)^{2}=(-0,015-0)^{2}=0,000225 \mu m
$$

Selection Standard Deviation

$$
s\left(x_{i}\right)=\sqrt{\frac{\sum_{i=1}^{n}\left(x_{i}-\bar{x}\right)^{2}}{n-1}}=\sqrt{\frac{0,027099}{2-1}}=0,0212 \mu \mathrm{m}
$$

In the case of this component, the change in surface roughness has already begun to occur when the pressure is reduced to 80 bar. At this pressure, the surface roughness deteriorated, but the measured Ra value was still within the critical roughness limit, which is $0.25 \mu \mathrm{m}$ for this component. Furthermore, the pressure was reduced to $30 \mathrm{bar}$. This pressure has already deteriorated the surface roughness that has exceeded the scrap limit. The average surface roughness at a working pressure of 30 bar was $0.284 \mu \mathrm{m}$, which is $0.034 \mu \mathrm{m}$ beyond the surface roughness limit.

At a working pressure of 10 bar, we reached an average surface roughness value of $0.305 \mu \mathrm{m}$, which is $0.055 \mu \mathrm{m}$ beyond scrap. Subsequently, the measurement deviations of each measurement surface were measured at a given working pressure.

In the case of part 2, the changes in surface roughness began to manifest itself as soon as the first working pressure was reduced but remained within the limit tolerance. However, the other two working pressure reductions have resulted in a deterioration of surface quality below the tolerance limit for scrap.

Component \# 2 is considerably larger in diameter than part \# 1, so more material is removed at the same time in the machining process itself, so in this case, the cooling pressure plays a significantly greater role in both part \# 1 and largely affects the surface roughness quality of the workpiece. Thus, a cooling pressure of 120 bar is appropriate for this component.

\subsection{Measurement of Part \# 2 by Alicona InfiniteFocus}

Because of the significant deterioration in surface roughness in reducing coolant pressure in the process of machining part 2 and the associated other possible surface defects, it was decided to perform surface sensing with the Alicona InfiniteFocus. Reducing the coolant pressure when machining the functional surface of part 2 has had a major impact on the roughness of the workpiece surface. Thus, it was exactly the opposite of component 1 , in which the reduction of the coolant pressure had no effect on the surface roughness. That is why we have chosen only part no. 2 for measuring with the Alicona InfiniteFocus, which could cause other defects in the surface quality of the workpiece due to pressure reduction. 
Table 3. Measured Results on Alicona for Part 2

\begin{tabular}{|c|c|c|}
\hline $\begin{array}{c}\text { Pressure } \\
(\mathbf{b a r})\end{array}$ & $\begin{array}{c}\text { Surface Roughness } \\
\mathbf{R a}(\boldsymbol{\mu m})\end{array}$ & $\begin{array}{c}\text { Selective Standard } \\
\text { Deviation }(\boldsymbol{\mu m})\end{array}$ \\
\hline 120 & 0,241 & $\pm 0,0304$ \\
\hline 80 & 0,287 & $\pm 0,0212$ \\
\hline 30 & 0,391 & $\pm 0,0007$ \\
\hline 10 & 0,468 & $\pm 0,0157$ \\
\hline
\end{tabular}

\section{Example of standard deviation calculation}

Selection average

$$
\bar{x}=\frac{\sum_{i=1}^{n} d_{i}}{n}=\frac{0,481}{2}=0,241 \mu \mathrm{m}
$$

Deviation $\Delta \mathrm{xi}$

$$
\Delta x_{i}=x_{i}-\bar{x}=0,219-0,2405=-0,0215 \mu m
$$

Quadratic deviation $\Delta x_{i}^{2}$

$$
\Delta x_{i}^{2}=\left(x_{i}-\bar{x}\right)^{2}=(-0,0215-0)^{2}=0,00046225 \mu m
$$

Selection Standard Deviation

$$
s\left(x_{i}\right)=\sqrt{\frac{\sum_{i=1}^{n}\left(x_{i}-\bar{x}\right)^{2}}{n-1}}=\sqrt{\frac{0,0009245}{2-1}}=0,0304 \mu \mathrm{m}
$$

When measured with the Alicona InfiniteFocus, it was found that the roughness limit for scrap was only at a working pressure of 120 bar. Other specimens made with gradual pressure reduction to a minimum exceeded the scrap rate in terms of surface roughness. The measurement was somewhat more demanding than the Mitutoyo roughness measurement. In this case, there was a need for a specialized, trained person who thoroughly explained the work with a very expensive device and trained to work with it. Only 2D surface scanning was performed, as 3D scanning would be unnecessary and time consuming to use the experiment. At a minimum pressure of $10 \mathrm{bar}$, the average surface roughness $\mathrm{Ra}$ of $0.468 \mu \mathrm{m}$ was measured, which corresponds to a deterioration of the surface by more than half compared to the limit tolerance. After the measurement, the results were processed in a table and then the individual measurement deviations were calculated. Due to other defects on the surface of the component than the defect of the surface roughness. The surface of the part was scanned and the surfaces produced at four different pressures were compared. In the case of part 2, the reduction of the coolant pressure also significantly influenced the chip formation. In view of this, it has been assumed that there is a possibility of other defects on the surface of the component, which may result in scrap of the component.

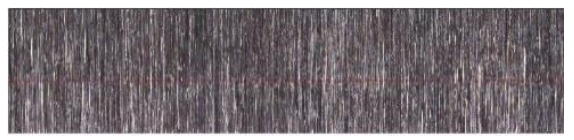

Fig. 7. Surface at pressure 120 bar

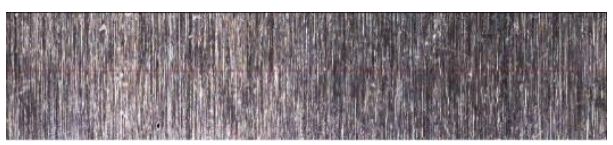

Fig. 8. Surface at pressure 80 bar 
No imperfections in the surface quality can be seen in the image taken with the part at 120 bar. The surface is completely homogeneous with no signs of damage. The average roughness was $0.2405 \mu \mathrm{m}$, which also corresponds to the surface quality. In the case of a pressure of 120 bar, the chip was crumbly and broken off in small pieces from the cut point, thus not having any chance to damage the surface of the component.

When the pressure dropped to 80 bar, the average surface roughness below the scrap rate dropped to $0.2865 \mu \mathrm{m}$, resulting in the scanned surface of the component. Also, slight scratches are visible on the surface due to deterioration of the chip and its exit from the cut. However, this is not yet an eye-detectable defect.

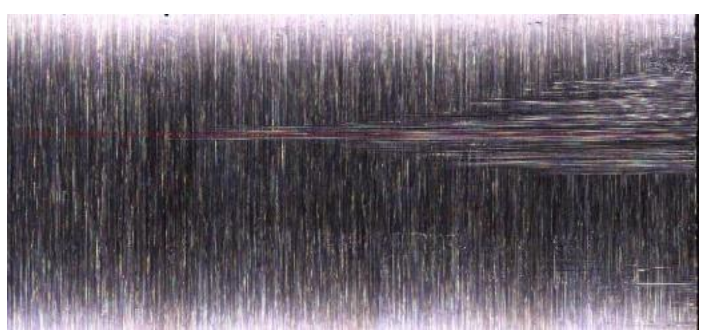

Fig. 9. Surface at pressure 30 bar

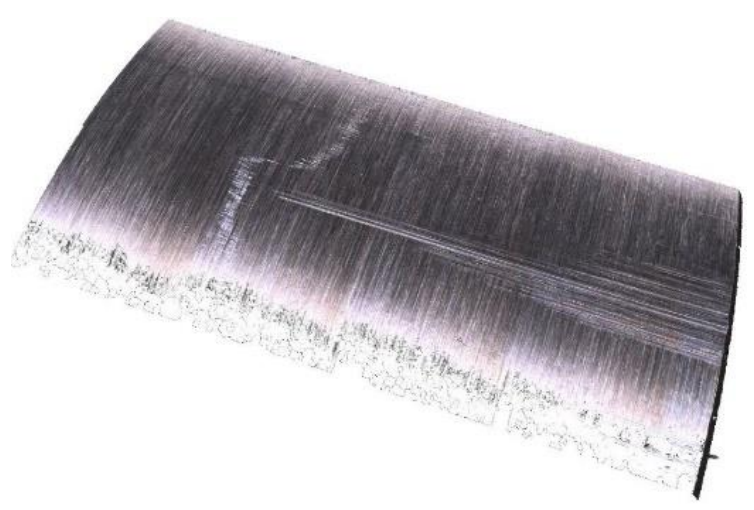

Fig. 10. Surface at pressure 210 bar

At a pressure of 30 and 10 bar, the surface roughness value has fallen far beyond the reject rate. In all images, there are large bruises on the right side of the scanned surface that are caused by poor chip formation. This is not cloudy, so it does not break off at a working pressure of 120 bar but wraps on the workpiece at the point of cut. Upon completion of the operations performed by the main spindle, the workpiece is separated from the base material by slitting. The critical moment occurs when the workpiece takes over the secondary spindle. The wound chip also travels with the workpiece where, when the workpiece is attached to the chuck, the chip is pushed into the surface of the workpiece material, thereby deteriorating the surface and thus becoming a scrap.

In the case of a surface image produced at a pressure of $10 \mathrm{bar}$, a large scratch resulting from poor chip exit from the cut point is also visible, including the squeeze. This scratch also causes a deterioration of the surface quality and thus becomes a scrap from the workpiece. 


\section{Discussion of Results}

Two measurements were made on part number 2 due to deterioration in surface quality. The first was made in the factory on the MITUTOYO SJ-410 roughness gauge (profile roughness meter). The second was done on an Alicona InfiniteFocus (optical microscope) measuring instrument. Samples for measurement were produced at four different pressures. From the highest working pressure (120 bar) to the lowest possible working pressure (10 bar). The following table 4 compares the measured values on both measuring instruments.

At a pressure of 120 bar, the measured values are within the tolerance for the desired quality of $\mathrm{Ra} 0.25 \mu \mathrm{m}$. However, when the pressure is reduced to $80 \mathrm{bar}$, the measured results differ slightly. When measured in the Mitutoyo Roughness Tester, both values were still within the tolerance for the required surface roughness, while the measurements measured with the Alicona InfiniteFocus measured both below the required surface quality. For the other two pressures (30 and 10 bar), the measured values have gone beyond the reject rate for both measuring devices.

Measurement with the Alicona InfiniteFocus was visibly more accurate than the MITUTOYO, but at the expense of time. The roughness measurement took place directly in the production and the preparation and measurement itself took about $1 \mathrm{~min}$. In the Alicona InfiniteFocus, it was difficult to prepare for the measurement itself, and the subsequent surface scanning took several minutes.

Table 4. Comparison of Measured Values for Part \# 2

\begin{tabular}{|c|c|c|c|c|}
\hline $\begin{array}{c}\text { Pressure } \\
(\mathbf{b a r})\end{array}$ & \multicolumn{2}{|c|}{$\begin{array}{c}\text { Surface Roughness at } \\
\text { MITUTOYO Ra }(\boldsymbol{\mu m})\end{array}$} & $\begin{array}{c}\text { Surface Roughness at Alicona } \\
\text { InfiniteFocus Ra }(\boldsymbol{\mu m})\end{array}$ \\
\hline 120 & 0,174 & $\pm 0,0212$ & 0,2405 & $\pm 0,0304$ \\
\hline 80 & 0,205 & $\pm 0,0078$ & 0,2865 & $\pm 0,0212$ \\
\hline 30 & 0,284 & $\pm 0,0212$ & 0,3905 & $\pm 0,0007$ \\
\hline 10 & 0,311 & $\pm 0,0757$ & 0,468 & $\pm 0,0157$ \\
\hline
\end{tabular}

\section{Conclusion}

The challenge was to find out how high-pressure cooling would affect the surface roughness, and what the required working pressure of the external high pressure CHAV $160 / 150$ is sufficient to achieve the required roughness quality of the workpiece produced by STAR SR-32J CNC machining center STAR STAR. Two types of components were manufactured for the experiment. For each of them, the working pressure was gradually reduced from the current maximum pressure to the minimum possible working pressure. For component \# 1 (gas meter rod), the pressure was gradually reduced by 20 bar from 150 bar to a minimum of 10 bar. A total of 8 samples were produced at different pressures. These samples were subsequently measured directly in the MITUTOYO roughness tester. The original assumption was that changes in surface roughness would start to appear at about 70 bar (half). In the case of part 1, this was not the case even with a reduction to a minimum working pressure of 10 bar. For all workpieces created at eight pressures, the roughness quality did not exceed the reject limit $\mathrm{Ra} 0.375 \mu \mathrm{m}$. When the pressure was reduced to a minimum (10 bar), the measured average roughness with a sample standard deviation of $\mathrm{Ra}=0.130 \pm 0.0095 \mu \mathrm{m}$ was all due to the minimum material removal of the workpiece.

For component \# 2 (gas control valve housing), samples were produced at only 4 different pressures $(120,80,30$, and 10 bar) due to larger component sizes and associated higher manufacturing costs. In Part 2, changes in surface roughness began to appear when 
the pressure was reduced to 70 bar. For this reason, two measurements were performed on part \# 2. The first on the MITUTOYO Roughness Tester right in the factory and the second on the Alicona InfiniteFocus special optical measuring device. The results are slightly different due to the different accuracy of the measuring devices, so a comparison of the measured results in Table 4 was made. In contrast, the Alicona InfiniteFocus has a Ra value of $0.2865 \pm 0.0212$, which is beyond the surface roughness tolerance. For the following two pressures (30 and 10 bar), the values of the drop are below the required surface roughness quality. The cooling pressure reduction in this case also affected the chip formation, which was not turbid, dropped from the cut point, where it was wrapped and subsequently formed scratches and bruises on the resulting surface. This caused a deterioration in surface quality. For this reason, surface images were taken on an Alicona InfiniteFocus measuring device that detected the defects. The images were then compared.

From the economic point of view, it is possible to consider the reduction of the pressure of the cooling medium in the case of part 1 and thus the reduction of the operation costs of the high pressure equipment CHAV 160/150. In the case of part 2, the working pressure of 120 bar is completely in place and it cannot be considered to be reduced as the surface roughness deteriorates at the first reduction.

Article has been done in connection with project from the means of state budget of the Czech Republic and by project Students Grant Competition SP2019/60 Modern and Productive Machining and Metrology financed by the Ministry of Education, Youth and Sports and Faculty of Mechanical Engineering VŠB-TUO.

\section{References}

1. https://www.starmicronics.de/en/produkte/sr_32j/ (cited in 11.04.2019)

2. https://www.hytek.cz/chlazeni-nastroju.php (cited in 10.04.2019)

3. https://shop.mitutoyo.cz/web/mitutoyo/cs_CZ/keywords.xhtml?result=1557923115884 \&showResult=1 (cited in 14.04.2019)

4. https://www.alicona.com/products/infinitefocus/?fbclid=IwAR15ZRmXp7jvTuovs0GL NaM3f_7yRDWCXEOZCbUi0Y86mpWPQi64QHkk5sg (cited in14.04.2019)

5. http://www.digitovarna.cz/clanek-84/komplexni-hodnoceni-jakostipovrchu.html?fbclid=IwAR3bLlEOwqrabRiYg5RJw2UH2xxw2qR1nttCsaqE6rE79128 JnN4BmJtC6I (cited in 10.04.2019)

6. R. Cep, A. Janasek, A. Sliva, M. Neslusan, M. Binder, Tehnički vjesnik - Technical Gazette, 20 (2013)

7. M. Šajgalik, A. Czan, M. Drbul, I. Danis, M. Miklos, O. Babik, R. Joch, Machining Innovations Conf. for aerospace ind. (Elsevier, 2017)

8. M. Gombar, A. Vagaska, M. Harnicarova, J. Valicek, M. Kusnerova, A. Czan, J. Kmec, 9, 1 (2019) 